\title{
Qualitative and Quantitative Determination of Various Extracts of Ocimum basilicum L. Leaves
}

\author{
Balakrishnan Purushothaman ${ }^{1,2^{*}}$, Nagarasan Suganthi ${ }^{2}$ and Kumaran Shanmugam ${ }^{1}$ \\ 1 Department of Biotechnology, Periyar Maniammai Institute of Science and Technology, Vallam, \\ Thanjavur-613 403, Tamil Nadu, India; vinakspurushoth@gmail.com \\ ${ }^{2}$ TanBio R and D Solution, Periyar Technology Business Incubator, Vallam, Thanjavur - 613 403, \\ Tamil Nadu, India
}

\begin{abstract}
Ocimum basilicum L. (Lamiaceae) commonly known as basil possesses various medicinal activities to treat headache, diarrhoea, kidney malfunctions, diabeties, cancer and several pharmacological activities. These are mainly due to the various chemically diversified constituents present in it. In order to evaluate the chemical composition of basil leaves, the dried leaves were extracted with petroleum ether, chloroform, ethyl acetate, methanol and water by Soxhlet's extraction. The extracts were screened for the qualitative determination by preliminary phytochemical screening. Quantitative determination was also performed for the total alkaloids, flavonoids, phenols, saponins and tannins. Amongst the extracts, methanol $(\mathrm{MeOH})$ was identified to contain various classes of secondary metabolites, so GCMS analysis was performed on the $\mathrm{MeOH}$ extract. The results revealed that chemical constituents claimed for various biological activities were present.
\end{abstract}

Keywords: Chemical Constituents, GCMS, Ocimum basilicum L., Qualitative, Quantitative

\section{Introduction}

Ocimum basilicum L. (also called basil) belongs to Lamiaceae, is a culinary herb which is highly spread across Southeast Asia and worldwide. From ancient times, it is widely used to treat various ailments due to its versatile medicinal properties $\stackrel{1,2}{2}$. Traditionally, it is used as folk medicine and Uyghur medicine in Turkey; treating pimples, headaches and kidney malfunctions in India; treating aches and pains in Bulgarian folk medicine, Sedative in Spain ${ }^{-}$. It is also used in the treatment of insect stings, snake bites and skin infections externally. It is also used as ornamental and kitchen herb for the aroma present in it. Essential oils extracted from basil leaves have high aroma and used as herbal flavours in most of the food products ${ }^{4}$. It possesses various pharmacological activities such as antimicrobial, anti-insecticidal, antioxidant, anti-inflammatory, anti-hyperlipidemic, antidiabetic, anticonvulsant, antiplatelet, anti-thrombotic, immune-modulatory, cytotoxicity and anti-cancer. These activities are mainly due to the various chemically diversified constituents present in it $\underline{\underline{5}}^{-\underline{9}}$. Alkaloids, flavonoids, phenols, terpenoids are present in basil leaves which have potent medicinal use $\underline{10}, \underline{11}$.

This study was designed to evaluate the chemical composition of basil leaves with different solvents such as petroleum ether, chloroform, ethyl acetate, methanol and water. Qualitative and quantitative determination of chemical constituents were evaluated through standard procedures for all the five extracts.

Total alkaloids, flavonoids, phenols, tannins and saponin contents were determined $\underline{12}, \underline{13}$. In which, Methanol $(\mathrm{MeOH})$ extract showed the high percentage yield of different chemical constituents. In order to quantify, $\mathrm{MeOH}$ extract was subject to Gas chromatography coupled with Mass spectrometer with suitable working conditions $\underline{\underline{14}}$.

\section{${ }^{*}$ Author for correspondence}




\section{Materials and Methods}

\subsection{Plant Collection}

Matured healthy leaves of Ocimum basilicum L. were collected from a botanical garden in Thanjavur, Tamil $\mathrm{Nadu}$, India and authenticated.

\subsection{Chemicals and Glassware}

The solvents used were of analytical grade (Nice chemicals). Glassware used were sterilized and graduations were accurate.

\subsection{Extraction}

The collected plant leaves were washed, shade dried and ground in a blender with $2 \mathrm{~mm}$ dia mesh size. The powdered samples of weight, each $100 \mathrm{~g}$ were extracted continuously with $500 \mathrm{ml}$ of petroleum ether, chloroform, ethyl acetate, methanol and aqueous $(1: 5 \mathrm{w} / \mathrm{v})$ in Soxhlet's apparatus. The process was continued for about 24 hours with a temperature below the boiling point of the solvent. The extracts were collected and filtered through Whatmann no.1 filter paper. Then the filtrate was concentrated in a rotary vacuum evaporator and stored in dark bottles and kept at $-20^{\circ} \mathrm{C}$ till further use ${ }^{15}$.

\subsection{Qualitative Determination of Chemical Constituents of Ocimum basilicum Leaf Extracts $\underline{16}, \underline{17}$}

\subsubsection{Test for Alkaloids}

\section{Wagner's Test}

To a 2-3 ml of plant extract, few drops of Wagner's reagent was added and kept undisturbed for 3-4 minutes. The reddish brown precipitate indicates the presence of alkaloid.

\section{Mayer's Test}

To a 2-3 $\mathrm{ml}$ of plant extracts, few drops of Mayer's reagent was added and kept undisturbed for 3-4 minutes. The formation of precipitate indicates the presence of alkaloid.

\subsubsection{Test for Flavonoids}

\section{Sodium Hydroxide Test}

To a $2-3 \mathrm{ml}$ of plant extract, $2 \mathrm{ml}$ of $10 \%$ sodium hydroxide solution was added to form an intense yellow color which would be turned to colorless in addition of diluted hydrochloric acid, this marks the presence of flavonoids.

\subsubsection{Test for Terpenes}

\section{Copper Acetate Test}

To a $3 \mathrm{ml}$ of plant extract, 8-10 drops of copper acetate solution was added. The emerald green color indicates the presence of terpenes.

\subsubsection{Tests for Carbohydrates}

\section{Molish's Test}

To a 2-3 $\mathrm{ml}$ of plant extract, a few drops of $\alpha$-napthol solution was added and shaken well to which a few drops of concentrated sulphuric acid were added along the sides of the test tube. The formation of a violet ring at the junction indicates the presence of carbohydrates.

\subsubsection{Tests for Protein}

\section{Biuret's Test}

To a 2-3 $\mathrm{ml}$ of plant extract, a few drops of $4 \%$ sodium hydroxide and $1 \%$ Copper sulphate solution was added. Appearance of Violet or pink color indicates the presence of proteins.

\section{Millon's Test}

To a $3 \mathrm{ml}$ of plant extract, a few drops of million's reagent was added and heated gently. The appearance of reddish brown coloration indicates the presence of proteins.

\subsubsection{Tests for Amino Acid}

\section{Ninhydrin Test}

To $1 \mathrm{ml}$ of plant extract, a few drops of 5\% Ninhydrin solution was added and the mixture was heated for about 8-10 min. Appearance of purple or blue color indicates the presence of amino acid. 


\subsubsection{Test for Fats and Oils (Fixed)}

\section{Spot Test}

A small quantity of extract was pressed between two Whatmann No.1 filter papers for about $2 \mathrm{~min}$. The oil stain on the paper indicates the presence of fixed oils.

\section{Saponification Test}

To a 2-3 $\mathrm{ml}$ of plant extract, $0.5 \mathrm{~N}$ alcoholic potassium hydroxide solution along with 2 drops of phenolphthalein was added and heated for about $2 \mathrm{hrs}$. The formation of soap or partial neutralization of alkali indicates the presence of fixed oils and fats.

\subsubsection{Test for Steroids}

\section{Salkowski Tests}

To a 2-3 $\mathrm{ml}$ of plant extract, $2 \mathrm{ml}$ of chloroform \& $2 \mathrm{ml}$ of concentrated sulphuric acid was added and shaken well. The chloroform layer appears red and acid layer shows greenish yellow fluorescence which shows the presence of steroids.

\subsubsection{Test for Cardiac Glycosides}

\section{KellarKillani's test}

A few $\mathrm{ml}$ of plant extracts was dissolved in water with Glacial acetic acid and ferric chloride and concentrated sulphuric acid. The formation of brown ring at the junction indicates the presence of cardiac glycosides.

\subsubsection{Test for Phenols and Tannins}

\section{Ferric Chloride Test}

To a $0.5 \mathrm{ml}$ of plant extract, $5 \mathrm{ml}$ of $\mathrm{D} . \mathrm{H}_{2} \mathrm{O}$ was added and boiled for $10 \mathrm{~min}$. To the $2 \mathrm{ml}$ of collected filtrate, a few drops of $10 \%$ ferric chloride solution were added. Appearance of greenish blue or violet color indicates the presence of a phenolic hydroxyl group.

\section{Lead Acetate Test}

To a 2-3 $\mathrm{ml}$ of plant extract, $3 \mathrm{ml}$ of lead acetate solution was added. The occurrence of white precipitate indicates the presence of tannins and phenols.

\subsubsection{Test for Saponins}

\section{Foam Test}

To a few quantity of the plant sample, respective amount of water was added and shaken vigorously for about $10 \mathrm{~min}$. The observation of persistent stable foam indicates the presence of saponins.

\subsection{Quantitative Determination of Chemical Constituents of Ocimum basilicum Leaf Extracts}

\subsubsection{Determination of Total Alkaloids}

$1 \mathrm{mg} / \mathrm{ml}$ equivalent of plant sample was dissolved in a dimethyl sulfoxide and $1 \mathrm{ml}$ of $2 \mathrm{~N}$ hydrochloric acid was added and the mixture was filtered. The filtrate was transferred to a separating funnel, $5 \mathrm{ml}$ of bromocresol green solution and $5 \mathrm{ml}$ of phosphate buffer were added. The mixture was shaken vigorously with $1,2,3$ and $4 \mathrm{ml}$ chloroform and collected in a 10$\mathrm{ml}$ volumetric flask and diluted to the volume with chloroform. The absorbance for test and standard solutions were determined against the reagent blank at $470 \mathrm{~nm}$ with an UV-Vis spectrophotometer. A set of reference standard solutions of atropine (20, 40, 60, 80 and $100 \mu \mathrm{g} / \mathrm{ml}$ ) were prepared in the same manner as described earlier $\underline{16}$.

\subsubsection{Determination of Total flavonoids}

Total flavonoids were determined by the aluminium chloride colorimetric assay. The reaction mixture consists of $1 \mathrm{ml}$ of extract and $4 \mathrm{ml}$ of distilled water was subjected to the $0.3 \mathrm{ml}$ of $5 \%$ sodium nitrite solution. After 5 minutes, $0.3 \mathrm{ml}$ of $10 \%$ aluminium chloride was mixed. After 5 minutes, $2 \mathrm{ml}$ of $1 \mathrm{M}$ Sodium hydroxide was treated and diluted to $10 \mathrm{ml}$ with distilled water. The absorbance for test and standard solutions were determined against the reagent blank at $510 \mathrm{~nm}$ with an UV-Vis spectrophotometer. A set of reference standard solutions of quercetin (20,40,60, 80 and 100 $\mu \mathrm{g} / \mathrm{ml}$ ) were prepared in the same manner as described earlier $\underline{18}$.

\subsubsection{Determination of Total Saponins}

Add $20 \mathrm{~g}$ of powdered sample in a conical flask containing $100 \mathrm{ml}$ of $20 \%$ aqueous ethanol. The 
solution was heated for $4 \mathrm{~h}$ with constant stirring at $55^{\circ} \mathrm{C}$. Then the solution was filtered and extracted with $200 \mathrm{ml}$ of $20 \%$ ethanol. After that, both extracts were mixed and solvent was evaporated till it reached $40 \mathrm{ml}$ volume of extract. The concentrated filtrate was further extracted with $20 \mathrm{ml}$ of diethyl, aqueous layer was recovered while the ether layer was discarded. The aqueous extracts were purified by adding $60 \mathrm{ml}$ $\mathrm{n}$-butanol. Then, it was washed with twice $10 \mathrm{ml}$ of $5 \%$ aqueous sodium chloride ${ }^{\underline{19}}$.

\subsubsection{Determination of Total Tannins}

The total tannins were determined by Folin-Ciocalteu method. About $0.1 \mathrm{ml}$ of the sample was subjected to a $7.5 \mathrm{ml}$ of distilled water and $0.5 \mathrm{ml}$ of Folin-Ciocalteu phenol reagent and $1 \mathrm{ml}$ of $35 \% \mathrm{Na}_{2} \mathrm{CO}_{3}$ solution and diluted to $10 \mathrm{ml}$ with distilled water. The mixture was shaken well and kept at room temperature for 30 min. Absorbance for test and standard solutions were measured against the blank at $725 \mathrm{~nm}$ with an UVVis spectrophotometer. A set of reference standard solutions of Gallic acid (20,40, 60, 80 and $100 \mu \mathrm{g} /$ $\mathrm{ml})$ were prepared in the same manner as described earlier $\underline{20}$.

\subsubsection{Determination of Total Phenolics}

The total phenolics was determined by Folin-Ciocalteu assay method. About $1 \mathrm{ml}$ of extract was added with 9 $\mathrm{ml}$ of distilled water \& $1 \mathrm{ml}$ of Folin-Ciocalteu phenol reagent and shaken well. After 5 minutes, $10 \mathrm{ml}$ of $7 \%$ $\mathrm{Na}_{2} \mathrm{CO}_{3}$ solution was treated to the mixture and the volume were made up to $25 \mathrm{ml}$. Incubated for $90 \mathrm{~min}$ at room temperature and the absorbance for test and standard solutions were determined against the reagent blank at $550 \mathrm{~nm}$ with an UV-Vis spectrophotometer. A set of standard solutions of Gallic acid (20, 40, 40, 60, 80 and $100 \mu \mathrm{g} / \mathrm{ml}$ ) were prepared in the same manner as described earlier $\underline{21}$.

\subsubsection{GC-MS Analysis}

The identification and quantification of basil chemical constituents were evaluated by Gas chromatography coupled with Mass spectrometry QP2010 plus, Shimadzu, Japan equipped with RTX-5 MS GC capillary column (5\% diphenyl/ 95\% dimethyl polysiloxane) of $0.5 \mu \mathrm{m}$ dia and $30 \mathrm{~m}$ length. GC working conditions: The temperature was kept between $40-290^{\circ} \mathrm{C}$ with a gradual increase of $8^{\circ} \mathrm{C} / \mathrm{min}$. Column oven and injection temperatures were set at $100^{\circ} \mathrm{C}$ and $270^{\circ} \mathrm{C}$ respectively. Injection mode was set as split with a ratio of 20; Helium was used as carrier gas (mobile phase) with a flow rate of $1 \mathrm{ml} / \mathrm{min}$. MS working conditions: ion source and interface temperatures were set at 200 and $260^{\circ} \mathrm{C}$. Solvent cut-off time was set as $4 \mathrm{~min}$ and detector voltage was set at $0.1 \mathrm{kV}$. Injection conditions: $1 \mu \mathrm{L}$ injection volume; $10 \mu \mathrm{L}$ injection syringe; injection temperature at $240^{\circ} \mathrm{C}$; mass range at $20-300$ $\mathrm{m} / \mathrm{z}$. The analytes were matched with the NIST and

Table 1. Qualitative determination of chemical constituents of Ocimum basilicum Leaf extracts

\begin{tabular}{cccccccc} 
S.No & $\begin{array}{c}\text { Chemical } \\
\text { constituents }\end{array}$ & Test name & PE extract & CF extract & EA extract & $\begin{array}{c}\text { MeOH } \\
\text { extract }\end{array}$ & Aq extract \\
1. & Alkaloids & Wagner's test & + & + & + & ++ & + \\
2. & Flavonoids & Sodium hydroxide test & + & + & + & + & + \\
3. & Terpenoids & Copper acetate test & - & + & + & + & - \\
4. & Carbohydrates & Molisch's test & - & + & - & + & + \\
5. & Proteins & Biuret's test & - & + & - & ++ & + \\
6. & Amino acids & Millon's test & + & - & + & + & + \\
\hline
\end{tabular}




\begin{tabular}{|c|c|c|c|c|c|c|c|}
\hline \multirow{2}{*}{7.} & \multirow{2}{*}{ Fats and oils (Fixed) } & Spot test & ++ & + & - & + & - \\
\hline & & Soponification & - & - & - & - & + \\
\hline 8. & Steroids & Salkowski Test & + & + & + & + & + \\
\hline 9. & Cardiac glycosides & KellarKillani's test & + & + & + & + & + \\
\hline \multirow{3}{*}{10.} & \multirow{2}{*}{$\begin{array}{l}\text { Tannins and } \\
\text { Phenolics }\end{array}$} & Ferric chloride test & + & - & + & + & + \\
\hline & & Lead acetate test & + & + & ++ & ++ & + \\
\hline & Saponins & Foam test & + & - & + & ++ & ++ \\
\hline
\end{tabular}

Note: PE- Petroleum ether; CF- Chloroform; EA- Ethyl acetate; MeOH- Methanol; Aq- Aqueous; ++ denotes relatively high; + denotes present; - denotes not detected.

Wiley library for the similar hits of the basil chemical compositions $\underline{22}-\underline{24}$.

\section{Results and Discussion}

\subsection{Qualitative Determination}

Table 1 represents the presence of basil chemical constituents in various extracts such as petroleum ether, chloroform; ethyl acetate; methanol; aqueous. PE and EA extracts showed various class of secondary metabolites than CF extract but lesser that $\mathrm{MeOH}$ and aq extracts. Alkaloids, flavonoids, steroids, cardiac glycosides and phenolics were present in almost all the extracts. Comparatively, $\mathrm{MeOH}$ extract showed various chemical constituents of basil that the other extracts.

\subsection{Quantitative Determination}

Table 2 represents the quantitative determination of chemical constituents of Ocimum basilicum L leaf extracts in respect to total alkaloids, flavonoids, phenols, tannins and saponins content. Alkaloids, flavonoids, phenols and saponins were highly present in $\mathrm{MeOH}$ but saponin content was low. Comparatively, $\mathrm{MeOH}$ extracts showed more quantity of chemical constituents amongst all the extracts, so it was taken to the GCMS quantification. The values here are mentioned in percentage by converting $\mathrm{mg} / \mathrm{standard}$ gram equivalent.

\subsection{GC-MS Analysis}

Figure 1 and Table 3 represents the chromatogram and percentage composition of chemical constituents

Table 2. Quantitative determination of chemical constituents of Ocimum basilicum Leaf extracts

\begin{tabular}{|c|c|c|c|c|c|c|}
\hline \multirow{2}{*}{ S.No } & \multirow{2}{*}{ Extracts } & \multicolumn{5}{|c|}{ Quantitative determination of chemical constituents (\%) } \\
\hline & & Alkaloids & Flavanoids & Saponins & Tannins & Phenols \\
\hline 1. & PE extract & $1.85 \pm 0.5$ & $10.98 \pm 0.2$ & $7.8 \pm 0.9$ & $5.25 \pm 0.25$ & $18.25 \pm 0.35$ \\
\hline 2. & CF extract & $0.1 \pm 0.05$ & $11.58 \pm 1.8$ & $7.0 \pm 1.65$ & $4.1 \pm 0.65$ & $17.5 \pm 0.85$ \\
\hline 3. & EA extract & $0.8 \pm 0.2$ & $8.39 \pm 0.6$ & $6.15 \pm 0.25$ & $3.0 \pm 0.45$ & $20.2 \pm 0.25$ \\
\hline 4. & $\mathrm{MeOH}$ extract & $2.5 \pm 0.25$ & $16.35 \pm 1.5$ & $8.5 \pm 0.8$ & $2.5 \pm 0.35$ & $22.5 \pm 0.85$ \\
\hline 5. & Aq extract & $1.25 \pm 0.8$ & $15.6 \pm 0.5$ & $7.65 \pm 0.95$ & $3.2 \pm 0.85$ & $14.02 \pm 0.95$ \\
\hline
\end{tabular}

$\mathrm{n}=3$, values are in percentage, SEM 


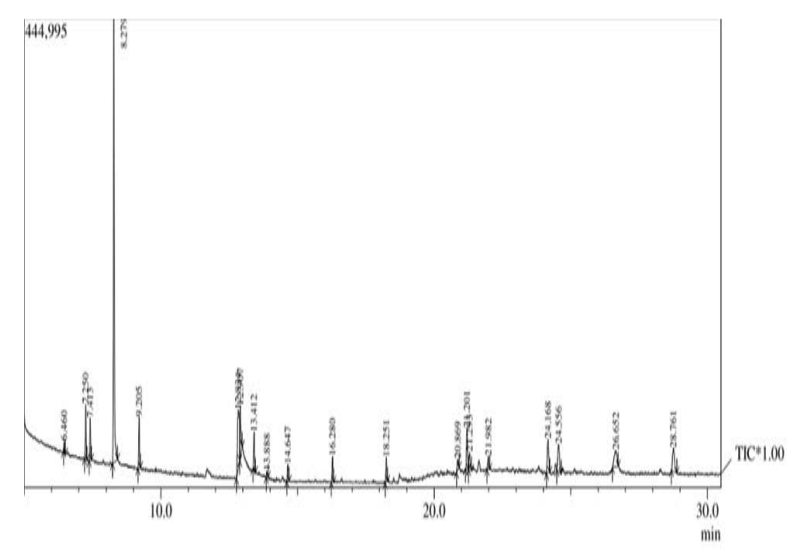

Figure 1. GCMS chromatogram of methanolic extract of Ocimum basilicum leaves. of methanol leaf extract of basil. The peaks in the chromatogram were compared with the Wiley and NIST database of spectrum installed with GCMS library. The results revealed the presence of chemical composition with area $\%$ and $\mathrm{m} / \mathrm{z}$ ratio with respect to their retention times.

Each component of the composition possesses unique retention times which vary in peak areas. The most abundant components in the methanol leaf extract were found to be eugenol, germacrene, $\beta$-elemene, gurjunene and menthol with higher peak area percentage. Mostly terpene alcohols and hydrocarbons were detected, and sesquiterpene also with considerable concentrations.

Table 3. Quantitative determination of chemical constituents of Ocimum basilicum Leaf MeOH extract by Gas chromatography Mass spectrometry

\begin{tabular}{|c|c|c|c|}
\hline Peak & Retention time & Area \% & Name \\
\hline 1 & 6.460 & 0.59 & MYCRENE \\
\hline 2 & 7.250 & 3.79 & EUCALYPTOL (1,8-CINEOLE) \\
\hline 3 & 7.413 & 3.16 & 1,3,6-OCTATRIENE, 3,7-DIMETHYL-, (E)- \\
\hline 4 & 8.279 & 38.14 & EUGENOL \\
\hline 5 & 9.205 & 3.88 & BICYCLO[2.2.1]HEPTAN-2-ONE, 1,7,7-TR \\
\hline 6 & 12.834 & 10.70 & GERMACRENE \\
\hline 7 & 12.907 & 5.01 & CYCLOHEXANEETHANOL,4-ETHENYL- \\
\hline 8 & 13.412 & 2.96 & BICYCLO[7.2.0]UNDEC-4-ENE,4,11,11-TR \\
\hline 9 & 13.888 & 0.44 & 1-PROPENE, 3-BROMO- \\
\hline 10 & 14.647 & 1.29 & 2,3,5,8,10,11-HEXAMETHYLENEDODECA \\
\hline 11 & 16.280 & 1.91 & BETA ELEMENE \\
\hline 12 & 18.251 & 1.82 & 9-DODECEN-1-OL, (Z)- \\
\hline 13 & 20.869 & 1.28 & BIS-(3,5,5-TRIMETHYLHEXYL) ETHER \\
\hline 14 & 21.201 & 4.16 & GURJUNENE \\
\hline 15 & 21.293 & 2.04 & 1,5-Dimethyl-1-vinyl-4-hexenyl butyrate \\
\hline 16 & 21.282 & 1.26 & LINALOOL FORMATE \\
\hline 17 & 24.168 & 4.39 & MENTHOL \\
\hline 18 & 24.556 & 4.31 & METHYL(Z) CINNAMATE \\
\hline 19 & 26.652 & 4.29 & 1,5-Pentanediol,O,O'-di(propargyloxycarbony \\
\hline 20 & 28.761 & 4.57 & 1-PENTANONE, 3-[4-(DIPHENYLMETHY \\
\hline
\end{tabular}




\section{Conclusion}

Ocimum basilicum L. leaf extracts were tested for the presence of medicinally important chemical constituents. The qualitative and quantitative determination of chemical constituents of basil leaf extracts were evaluated. GCMS analysis reveals the exact composition with $\mathrm{m} / \mathrm{z}$ ratio in respect to retention time. The results revealed that the methanol $(\mathrm{MeOH})$ is the most suitable solvent to extract the basil leaf essential oil with high yield of chemical constituents. Further investigation will be helpful in the isolation and characterization of these bio-active compounds and by exploring their pharmacological activities will lead to the development of new therapeutic drugs.

\section{Acknowledgement}

We thank TanBio R\&D solution, Periyar Technology Business Incubator, Vallam, Thanjavur for their kind support in analysing the samples.

\section{Conflicts of Interests}

The authors declare there is no any conflicts of interests.

\section{References}

1. Ladwani AMA, Salman M, Abdel Hameed ES. Chemical composition of Ocimum basilicum L. essential oil from different regions in the Kingdom of Saudi Arabia by using Gas chromatography mass spectrometer. Journal of Medicinal Plants Studies. 2018; 6(1):14-19.

2. Nagarasan S, Boominathan M. Invitro studies on the primitive pharmacological activities of Adhatodavasica. International Journal of Life Sciences. 2016; 4(3):379-85.

3. Hussain AI, Anwar F, Hussain ST, Przybylski R. Chemical composition, antioxidant and antimicrobial activities of basil (Ocimum basilicum) essential oils depends on seasonal variations. Food Chemistry. 2008; 108(3):986-95. https:// doi.org/10.1016/j.foodchem.2007.12.010 PMid:26065762

4. Navarro V, Villarreal ML, Rojas G, Lozoya X. Antimicrobial evaluation of some plants used in Mexican traditional medicine for the treatment of infectious diseases. Journal of Ethnopharmacology. 1996; 53(3):143-47. PMid: 8887021. https://doi.org/10.1016/0378-8741(96)01429-8

5. Purushothaman B, PrasannaSrinivasan R, Suganthi P, Ranganathan B, Gimbun J, Shanmugam K. A comprehensive review on Ocimum basilicum Journal of Natural Remedies. 2018; 8(3):41-55. https://doi.org/10.18311/jnr/2018/21324

6. Sethuraman J, Nehru H, Shanmugam K, Balakrishnanan P. Evaluation of potent phytochemicals and antidiabetic activity of Ficusracemosa L. World Journal of Pharmaceutical Research. 2017; 6(15):909-20. https:// doi:10.20959/wjpr201715-10140.

7. Balakrishnan P, Kumar GS, Ramalingam PS, Nagarasan S, Murugasan V, Shanmugam K. Distinctive pharmacological activities of Eclipta alba and it's coumestanwedolactone. Indo American Journal of Pharmaceutical Research. 2018; 5(4):2996-3002. https://doi:10.5281/zenodo.1231062.

8. Saranya T, Kalimuthu J, Balakrishnan P, Ramalingam PS, Parthasarathi $S$, et al., Isolation and characterisation of cellulolytic activity of bacteria and fungi from the soil of paper recycling unit at periyarmaniammai university. Indo American Journal of Pharmaceutical Research. 2017; 7(06). https://doi: 10.5281/ZENODO.2526699.

9. Rathnasamy S, Rufus AL, Purusothaman. Comparative studies on isolation and characterization of allinase from garlic and onion using PEGylation- A novel method. Asian Journal of Chemistry. 2014; 26(12):3733-5. https://doi. org/10.14233/ajchem.2014.17064

10. Mathew R, Sankar DP. Effect of methyl jasmonate and chitosan on growth characteristics of Ocimum basilicum L., Ocimum sanctum L. and Ocimum gratissimum L. Cell suspension cultures. African Journal of Biotechnology. 2012; 11(21):4759-66. https://doi.org/10.5897/AJB11.3183

11. Sundaramoorthy M, Prabaharan C, Balakrishnan P, Saravanan TS. Antibacterial and wound healing effects of semi-purified heart proteins from certain selective slaughter house animals. Indo American Journal of Pharmaceutical Research. 2014; 4(01).

12. Grayer RJ, Bryan SE, Veitch NC, Goldstone FJ, Paton A, Wollenweber E. External flavones in sweet basil, Ocimum basilicum, and related taxa. Phytochemistry. 1996; 43(5):1041-47.https://doi.org/10.1016/S00319422(96)00430-X

13. Nagarasan S, Boominathan M. Perspective Pharmacological Activities of LeucasAspera: An Indigenous Plant Species. Indo American Journal of Pharmaceutical Research. 2016; 6(09):6567-72.

14. Hossain MA, Kabir MJ, Salehuddin SM, Mizanur Rahman SM, Das AK, Singha SK, Alam K, Rahman A. Antibacterial properties of essential oils and methanol extracts of sweet basil Ocimum basilicum occurring in Bangladesh. Pharmaceutical Biology. 2010; 48(5):504-11. https://doi. org/10.3109/13880200903190977. Mid:20645791

15. Filip S, Vidović S, Vladić S, Pavlić B, Adamović D, Zeković Z. Chemical composition and antioxidant properties of Ocimum basilicum L. extracts obtained by supercritical carbon dioxide extraction: Drug exhausting method. The 
Journal of Supercritical Fluids. 2016; 109:20-5. https://doi. org/10.1016/j.supflu.2015.11.006

16. Ramalingam PS, Sagayaraj M, Ravichandiran P, Balakrishnanan P, Nagarasan S, Shanmugam K. Lipid peroxidation and anti-obesity activity of Nigella sativa seeds. World Journal of Pharmaceutical Research. 2017; 6(10):882-92. https://doi.org/10.20959/wjpr201710-9389

17. Pirbalouti AG, Mahdad E, Craker L. Effects of drying methods on qualitative and quantitative properties of essential oil of two basil landraces. Food Chemistry. 2013; 141(3):2440-49. https://doi.org/10.1016/j. foodchem.2013.05.098. PMid:23870979

18. Balakrishnan P, Musafargani TA, Subrahmanyam S, Shanmugam K. A perspective on bioactive compounds from Solanum trilobatum. Journal of Chemical and Pharmaceutical Research. 2015; 7(8):507-12.

19. Soni V, Jha AK, Dwivedi J, Soni P. Qualitative and quantitative determination of phytoconstituents in some antifertility herbs. Indian Journal of Pharmaceutical Sciences. 2018; 80(1):79-84. https://doi.org/10.4172/pharmaceuticalsciences. 1000332

20. Amrani S, Harnafi H, Gadi D, Mekhfi H, Legssyer A, Aziz $\mathrm{M}$, et al. Vasorelaxant and anti-platelet aggregation effects of aqueous Ocimum basilicum extract. Journal of
Ethanopharmacology. 2009; 125(1):157-62. https://doi. org/10.1016/j.jep.2009.05.043. PMid:19505553

21. Jayasinghe $\mathrm{C}$, Gotoh N, Aoki T, Wada S. Phenolics composition and antioxidant activity of Sweet Basil (Ocimum basilicum L.). Journal of Agricultural and Food Chemistry. 2003; 51(15):4442-9. https://doi.org/10.1021/jf034269o. PMid:12848523

22. Marotti M, Piccaglia, R, Giovanelli E. Differences in essential oil composition of Basil (Ocimum basilicum L.) Italian cultivars related to morphological characteristics. Journal of Agricultural and Food Chemistry. 1996; 44(12):3926-29. https://doi.org/10.1021/jf9601067

23. Kadhim MJ, Sosa AA, Hameed IH. Evaluation of antibacterial activity and bioactive chemical analysis of Ocimum basilicum using Fourier Transform Infrared (FT-IR) and Gas Chromatography- Mass Spectrometry (GC-MS) techniques. International Journal of Pharmacognosy and Phytochemical Research. 2016; 8(6):127-46. https://doi. org/10.5897/JPP2015.0366

24. Chalchat J-C, Özcan MM. Comparative essential oil composition of flowers, leaves and stems of basil (Ocimum basilicum L.) used as herb. Food Chemistry. 2008; 110(2):50103. https://doi.org/10.1016/j.foodchem.2008.02.018. PMid:26049245 